\title{
Socio-demographic determinants of leisure participation among female academicians in Universiti Putra Malaysia
}

\author{
Mahmud Z. Y. ${ }^{1}$, Minhat H. S. ${ }^{2}{ }^{*}$, Mahmud A. ${ }^{3}$ \\ 1, 2, 3 Department of Community Health, Faculty of Medicine and Health Sciences, University \\ Putra Malaysia, 43400 UPM Serdang, Selangor Darul Ehsan, Malaysia
}

\section{Keywords:}

Leisure

Female academicians

Socio-demography

UPM

Received: 27 July 2014

Accepted: 28 July 2015

Published: 15 October 2015

\begin{abstract}
Leisure-time physical activity is termed the time to enjoy and get involved in desired activity without any obligation or duty. A total of 654 respondents participated in the study (response rate 75\%). Factors found associated with leisure participation were age, $(\mathrm{r}-0.281, p<0.001)$, years of service $(\mathrm{r}-0.229, p<0.001)$, ethnicity ( $\mathrm{t}=-3.170, p<0.001)$, religion ( $\mathrm{t}=4.347, p<0.001)$, marital status $(\mathrm{t}=2.905, p<$ $0.001)$ and academic position ( $\mathrm{t}=5.489, p=0.001)$. No association was found between the country of origin and social support, time constraints, accessibility to facilities, and health status with leisure participation. Social support from family ( $\mathrm{t}=-0.1084, p<0.854$ ), friends $(\mathrm{t}=-0.672, p<0.502)$. In non-physical activity, some of the variables were found significant, and other variables were insignificant. Multiple linear regression analysis reveals age (0.119 ) is the only predictor of leisure participation. The model explained $9.8 \%$ and $2.8 \%$ variance of leisure participation. The second model also ages, predicting leisure participation.
\end{abstract}

(C) 2015 The Author(s). Published by TAF Publishing.

\section{INTRODUCTION}

Despite the increase in women population, they face lot of challenges and constraints toward participation in leisure activities. Leisure-time physical activity is termed the time to enjoy and get involved in desired activity without any obligation or duty Cheung et al. [1]. It's been reported that majority of individual's spend less time in leisure physical activity especially in sports [2]. Studies show that lack of free time due to family responsibilities is a major constraint to leisure activity . In 2014 South East Asians reported the lowest prevalence of inadequate physical activity, $15.0 \%$ among men and $19.0 \%$ among women [3]. Leisure activity is an essential for physical health

* Corresponding author: Halimatus Sakdiah Minhat

E-mail: halimatus@upm.edu.my

The Author(s). Published by TAF Publishing. This is an Open Access article distributed under a https://creativecommons.org/licenses/by-nc-nd/4.0/ Creative Commons Attribution-Non-Commercial No Derivatives 4.0 International License 
and general well-being [4]. Leisure activities are important as they have been found to help reducing the incidence of dementia; such activities include reading, playing board games, playing a melody, and dancing.

Its been reported that low income women of age 25 to 35 years with children have limited opportunities for leisure and recreational activities [5]. Factors such as social support can inspire individuals to pledge and maintain certain activities such as leisure time and physical activity Oliveira et al., [6]. Social support is referred to as a social network purpose provided by members within a social network, and social networks normally relate to the number or incidence of contacts with family members, relatives, friends, and colleagues [7]. Social support help to increase high level of engagement into leisure-time physical activity.

\section{Leisure Activity}

A leisure activity is beneficial to health and general well- being. Cheung et al., [1] characterized leisure activities into physical forms, cognitive, social, and productive activities. Physical activities which include walking, running or any sports activity while cognitive activity includes reading and playing cards, and social activity involves going to shopping and attending exhibitions. Productive activity includes caring for pets, plants and doing voluntary work Cheung et al., [1]. However divided leisure activities into structure and unstructured activities. Structured activities included running, walking, jogging, scouting etc. while, unstructured activities included coming together with friends or family members, reading together books and listening to melodies.

Leisure- time physical activities has a great benefit to the body which give a long life span. [2] discovered more than half of the respondents $62.5 \%$ engaged in leisure- time physical activity at home and only small portion $3.0 \%$ engaged in recreational activities. Amongst the respondents, $44.0 \%$ of women spent thier leisure-time in non- physical activities such as going shopping, 56.7\% preferred to spend thier leisure time watching Televison, $13.6 \%$ preferred reading , $8.5 \%$ listening to music, $5.2 \%$ spent there time in sports activities and $1.8 \%$ spent thier time in activities such as walking [2].

Various factors such as socio-demographic factors are basic key in influencing leisure participation among women and men in the society. This study was examined and analysed using validated questionnaires that are reliable. The aim of this study is explore different factors that influence leisure participation among female academicians in UPM. However the contribution of this study which include; this study provides a body of knowledge as base line data for comparable study. Information obtained in this study generates awareness concerning the prevalence of leisure participation among working women, in general. This study also provide relevant information to the relevant authorities about the need for recreational and leisure facilities in the workplace and residents.

\section{MATERIALS AND METHOD}

A cross-sectional design was employed among female academicians in (UPM). Participants were selected by sample random sampling using SPSS software. Questionnaire used is validated and reliable consisting of six sections, sociodemographic factors social support, time constraints, accessibility to facilities, 
health status and non-physical activity. Socio-demography were measured based on simple frequencies and percentage, social support, time constraints variables were measured using a 5-point likert scale which ranging from 1 to 5 and non-physical activity were measured using a 5 point likert scale which ranging from 0 to 4 . Accessibility to facilities and health status were measured using normal scale (Yes=1, No=0). Data was collected from December 2014 to March 2015. The data was analyzed using Statistical Package for Social Science (SPSS) version 22.0 software. Simple descriptive, independent t- test and multiple linear logistics regression were used to determine predictor of leisure participation. The level of significance was set at 0.05 .

\section{Study Sample}

This was a cross-sectional study involving all of the female academicians in Universiti Putra Malaysia (UPM). Simple random sampling was done using SPSS software to select participants. Data were collected for the period of four months ranging from December 2014 to March 2015.

\section{Questionnaire}

A pre-test questionnaire (English version) with six sections was used for data collection. Information obtained on socio-demographic factors comprised of 7 items (ethnicity, marital status, religious, county of origin, age and year service). Social support questionnaire was established and modified for the purpose of obtaining information from social support family and friends. Social support from family members and friends Prociano and Heller (1983) is measured using 5 point Likert scale ranging from 1-5. 5= "Always," 4="Sometimes", 3= "Once in a while", 2= "Rarely" and 1= "Never". Social support scored were categorize into two low and high. Social support using mean score as cut of point. The instruments showed good internal consistency with a Cronbach's $\alpha$ value of 0.966 for social support from family and 0.962 from friends, time constraints at home 0.744 , at work place 0.876 , health status 0.641 and also information obtained on non-physical activity consisted of 3 variables which include time constraint at home and work, were measure using a 5 point Likert scales ranging from 1-5. 5= "Always," $4=$ "Sometimes", 3= "Once in a while", 2= "Rarely" and 1= "Never". Time constraints scored were categorized into two, low and high. Accessibility to facilities at home and work place and health status were measures using normal scale (Yes=1 No=0). Although non-physical activity comprised of 15 activities were measured using a 5 point likert scale ranging from 0 to 4 . $0=$ "Not at all", 1="Once a month", 2= "Once a week", 3= "Few day a week", 4= "Every day", also the instrument showed good internal consistency with a Cronbach's $\alpha$ value of 0.899 .

\section{Statistical Analysis}

The data was analysed using Statistical Package for Social science SPSS version 22.0 software. The level of significance was set at 0.05 . For the purpose of analysis, some of the variables such as social support from family and friends, time constraints at home and work place, accessibility to facilities at home and work place variables were categories into two groups like (low \& high), and also socio-demographic, variables were categories into two groups which include; religion (Islam \& non-Islam), marital status (married \& single), 
ethnicity (Malay \& non Malay), academic position (Senior lecturer \& lecturer). Similarly descriptive statistics which included the measures of central

TABLE 1. Distribution of characteristics of the respondents ( $N=654)$

\begin{tabular}{|c|c|c|}
\hline Factors & n (\%) & Mean \pm SD \\
\hline Age category (years) & & $42.21 \pm 8.55$ \\
\hline Less than 35 & $163(24.9)$ & \\
\hline $36-42$ & $192(29.4)$ & \\
\hline $43-49$ & $167(25.5)$ & \\
\hline Above 50 & $132(20.2)$ & \\
\hline Years of service & & $10.82 \pm 7.56$ \\
\hline $1-10$ & $353(54.0)$ & \\
\hline $11-20$ & $242(36.9)$ & \\
\hline $21-30$ & $47(7.2)$ & \\
\hline 31 Above & $12(1.8)$ & \\
\hline \multicolumn{3}{|l|}{ Ethnicity } \\
\hline Malay & $451(70.0)$ & \\
\hline Chinese & $116(17.7)$ & \\
\hline Indian & $62(9.5)$ & \\
\hline Others & $25(3.8)$ & \\
\hline \multicolumn{3}{|l|}{ Religion } \\
\hline Islam & $458(70.1)$ & \\
\hline Buddhism & $84(12.8)$ & \\
\hline Hinduism & $49(7.5)$ & \\
\hline Christianity & $62(9.5)$ & \\
\hline Others & $1(0.2)$ & \\
\hline \multicolumn{3}{|l|}{ Marital status } \\
\hline Married & $439(67.1)$ & \\
\hline Single & $140(21.4)$ & \\
\hline Divorcee & $27(4.1)$ & \\
\hline Widow & $48(7.3)$ & \\
\hline \multicolumn{3}{|l|}{ Position } \\
\hline Lecture & $158(24.2)$ & \\
\hline Senior lecture & $277(42.4)$ & \\
\hline Associate professor & $163(24.9)$ & \\
\hline Professor & $56(8.6)$ & \\
\hline \multicolumn{3}{|l|}{ Country of origin } \\
\hline Malaysia & $625(95.6)$ & \\
\hline Non-Malaysia & $29(4.4)$ & \\
\hline $\begin{array}{l}\text { Social support received from family } \\
\text { members }\end{array}$ & $204(31.2)$ & $37.49 \pm 8.83$ \\
\hline Low & $450(68.8)$ & \\
\hline \multicolumn{3}{|l|}{ High } \\
\hline Social support received from friends & & $37.49 \pm 8.83$ \\
\hline Low & $217(33.2)$ & \\
\hline High & $437(66.8)$ & \\
\hline
\end{tabular}


tendency, frequencies and Standard deviation (SD) were used. The independent $\mathrm{t}$-test analysis was done to determine the relationship between the dependent variable and independent variables and multiple linear logistics regression analysis was used to determine predictors of leisure participation.

\section{Ethical Considerations}

Ethical approval was obtained from the Ethics Committee for Research Involving Human Subjects of the Universiti Putra Malaysia. Jawatankuasa Etika Universiti Melibatkan Manusia (JKEUPM)' prior to data collection. An informed and written consent was obtained from all participants.

\section{RESULTS}

\section{Socio-Demography Factors}

Table 1 shows the distribution of the characteristics of the respondents. The mean (SD) age of the participants was $42.21 \pm 8.55$ years old and the mean of years of services was $10.82 \pm 7.56$. More than half of the participants were Malays (69.0\%), Muslims (70.0\%), married (67.1\%), holding a senior lecturer position (42.4\%), and local citizens of Malaysia (95.6\%). With regarding to social support from family members, $(68.8 \%)$ perceived high social support from family member's while, (31.2\%) perceived low social support from family members. For perceived social support from friends, (66.8\%) perceived high social support from friends while, (33.2\%) perceived low social support from friends.

\section{The correlation between age and years of services in leisure} participation in physical activity

Table 2 shows the correlation between age and leisure participation. The analysis reveals a significant negative association between age $(r=-0.281$, $\mathrm{p}=<0.001)$, and years of service $(\mathrm{r}=-0.229, p=<0.001)$ with leisure participation engagement during leisure time. Furthermore both of the associations were weak.

TABLE 2. The correlation between age and years of services in leisure participation in physical activity $(\mathrm{N}=654)$

\begin{tabular}{lcc}
\hline \hline Factors & \multicolumn{2}{c}{ leisure participation } \\
\cline { 2 - 3 } & -0.281 & $\boldsymbol{p}$ \\
\hline Age & & $0.001^{*}$ \\
$\begin{array}{l}\text { Years of } \\
\text { services }\end{array}$ & -0.229 & $0.001^{*}$ \\
\hline
\end{tabular}

* Significant level $p=0.05$

\section{Association between socio-demographic factors and leisure participation in physical activity}

Table 3 is shows the association between socio-demographic factors (ethnicity, religion, marital status, position and country of origin) and leisure participation among respondents. Significant associations were found between ethnicity $(\mathrm{t}=3.970, \mathrm{p}=0.001)$, religion $(\mathrm{t}=4.347, \mathrm{p}=0.001)$, marital status $(\mathrm{t}=2.905, \mathrm{p}=0.004)$ and academic position $(\mathrm{t}=5.489, \mathrm{p}=0.001)$ with 
involvement into leisure time. Higher mean scores were reported among non-

Malay (5.14 \pm 4.95$)$, non-Muslims (5.26 \pm 5.00$)$, single (4.86 \pm 4.97$)$ and lecturers (5.75 \pm 4.97$)$ compared to otherwise

TABLE 3: Association between socio-demographic factors and leisure participation in physical activity ( $\mathrm{N}=654)$

\begin{tabular}{|c|c|c|c|}
\hline Factors & Mean \pm SD & $\mathbf{t}$ & $\mathbf{P}$ \\
\hline \multicolumn{4}{|l|}{ Ethnicity } \\
\hline Malay & $3.73 \pm 3.83$ & 3.970 & $0.001^{*}$ \\
\hline Non-Malay & $5.14 \pm 4.95$ & & \\
\hline \multicolumn{4}{|l|}{ Religion } \\
\hline Islam & $3.70 \pm 3.80$ & 4.347 & $0.001^{*}$ \\
\hline Non-Islam & $5.26 \pm 5.00$ & & \\
\hline \multicolumn{4}{|l|}{ Marital status } \\
\hline Married & $3.83 \pm 3.82$ & 2.905 & $0.004^{*}$ \\
\hline Single & $4.86 \pm 4.97$ & & \\
\hline \multicolumn{4}{|l|}{ Position } \\
\hline Senior lecturers & $3.66 \pm 3.97$ & 5.489 & $0.001^{*}$ \\
\hline Lecturers & $5.75 \pm 4.73$ & & \\
\hline \multicolumn{4}{|l|}{ Country of origin } \\
\hline Malaysia & $4.13 \pm 4.17$ & 0.897 & 0.369 \\
\hline Non-Malaysia & $4.86 \pm 5.75$ & & \\
\hline \multicolumn{4}{|c|}{ Social support family } \\
\hline Low & $4.12 \pm 4.40$ & -0.184 & 0.854 \\
\hline High & $4.19 \pm 4.19$ & & \\
\hline \multicolumn{4}{|c|}{ Social support friends } \\
\hline Low & $4.01 \pm 4.32$ & -0.672 & 0.502 \\
\hline High & $4.25 \pm 4.23$ & & \\
\hline
\end{tabular}

Predicting factors for leisure participation in physical activity among female academicians in UPM

The multiple linear regression analysis was used to determine the predictors of leisure participation among female academician in UPM. During the final analysis four variables that were entered using "ENTER "method into the model; only age was found to be predicting leisure participation in physical activity among female academicians.

TABLE 4. Multiple linear regression showing predictor of leisure participation in physical activity ( $\mathrm{N}=654)$

\begin{tabular}{|c|c|c|c|c|c|c|c|}
\hline \multirow[t]{2}{*}{ Factors } & $\begin{array}{l}\text { Unstandardized } \\
\text { coefficient }\end{array}$ & $\begin{array}{c}\text { Standardized } \\
\text { coefficient }\end{array}$ & \multirow[t]{2}{*}{$\bar{T}$} & \multicolumn{2}{|c|}{$\begin{array}{l}\text { 95\% CI Confidence } \\
\text { interval }\end{array}$} & \multirow[t]{2}{*}{$\bar{p}$} & \multirow[t]{2}{*}{ 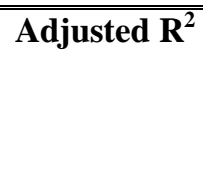 } \\
\hline & SE & Beta & & Lower & Upper & & \\
\hline
\end{tabular}




\begin{tabular}{|c|c|c|c|c|c|c|c|c|}
\hline Constant & 8.569 & 1.146 & & 7.480 & 6.320 & 10.819 & $0.001^{*}$ & $9.8 \%$ \\
\hline Age & -0.119 & 0.031 & -0.234 & -3.811 & -0180 & -0.058 & $0.001 *$ & \\
\hline
\end{tabular}

TABLE 5. Distribution of leisure participation among respondents according to non-physical activity $(\mathrm{N}=654)$

\begin{tabular}{|c|c|c|c|c|c|c|}
\hline Activities & $\begin{array}{l}0 \text { (not at } \\
\text { all) } \\
\quad n(\%)\end{array}$ & $\begin{array}{c}1 \text { (once a } \\
\text { month) } \\
\text { n (\%) }\end{array}$ & $\begin{array}{c}2 \text { (once a week) } \mathbf{n} \\
(\%)\end{array}$ & $\begin{array}{l}\text { (few days a } \\
\text { week } \\
\text { n }(\%)\end{array}$ & $\begin{array}{c}\text { 4(everyday) } \\
\text { n (\%) }\end{array}$ & Mean \pm SD \\
\hline Reading & $9(1.4)$ & $174(26.6)$ & $111(16.9)$ & $114(17.4)$ & $247(37.7)$ & $2.63 \pm 1.26$ \\
\hline Watching TV & $22(3.4)$ & $110(16.8)$ & 125 (19.1) & $105(16.0)$ & $292(44.7)$ & $2.82 \pm 1.25$ \\
\hline Listening to radio & $67(10.2)$ & $107(16.4)$ & $101(15.4)$ & $102(15.6)$ & $278(42.4)$ & $2.64 \pm 1.42$ \\
\hline Chatting & $33(5.0)$ & $145(22.2)$ & $158(24.1)$ & $150(22.9)$ & $168(25.7)$ & $2.42 \pm 1.22$ \\
\hline Shopping & $26(4.0)$ & $205(31.5)$ & $223(34.1)$ & $114(17.4)$ & $86(13.1)$ & $2.04 \pm 1.08$ \\
\hline Meeting relatives & 57 (8.7) & $259(39.6)$ & $200(30.6)$ & $95(14.5)$ & $43(6.6)$ & $1.71 \pm 1.03$ \\
\hline Exhibitions & $143(21.9)$ & $292(44.7)$ & $138(21.1)$ & $55(8.0)$ & $26(4.0)$ & $1.28 \pm 1.02$ \\
\hline Playing cards & $278(42.5)$ & $148(22.6)$ & $121(18.5)$ & $52(7.9)$ & $55(8.4)$ & $1.17 \pm 1.28$ \\
\hline Writing & $161(24.6)$ & $179(27.3)$ & $126(19.2)$ & $70(10.7)$ & $142(21.9)$ & $1.84 \pm 1.48$ \\
\hline Movies & $162(24.7)$ & $151(23.1)$ & $114(17.4)$ & $85(13.0)$ & $143(21.8)$ & $1.84 \pm 1.48$ \\
\hline Cooking & $157(24.0)$ & $143(22.9)$ & $96(14.7)$ & $79(12.1)$ & $176(27.4)$ & $1.97 \pm 1.54$ \\
\hline Sewing & $256(39.1)$ & $152(23.2)$ & $96(14.7)$ & $52(7.9)$ & $98(15.0)$ & $1.36 \pm 1.44$ \\
\hline Sleeping & $211(32.3)$ & $187(28.6)$ & $78(11.9)$ & $47(7.2)$ & $131(20.0)$ & $1.54 \pm 1.49$ \\
\hline Facial massage & $353(54.0)$ & 207 (31.7) & $54(8.2)$ & $21(3.2)$ & $19(2.9)$ & $0.69 \pm 0.96$ \\
\hline Browsing & $13(2.0)$ & $97(14.8)$ & $110(16.8)$ & $116(17.7)$ & $318(48.6)$ & $2.96 \pm 1.19$ \\
\hline Total mean & & & & & & $28.93 \pm 8.88$ \\
\hline
\end{tabular}

Predicting factors for leisure participation in physical activity among female academicians in UPM

Table 4 shows the final model for multiple linear regressions model and predictors of leisure participation. The predictive model for leisure participation in physical activity among female academician in UPM is: leisure participation Score (LPS) $=8.569,-0.119$ Age. This model shows a reduction in the LP by $-0.119(95 \% \mathrm{CI}=-0.180,-0.058)$ for every year increase in age. However the model can only explained $9.8 \%$ of leisure physical activity.

\section{Distribution of leisure participation among respondents according to non-physical activity}

The top five (5) in non-physical activities that were conducted on a daily basis were browsing, which had the highest mean score, $2.96 \pm 1.194$, watching television $2.82 \pm 1.26$, listening to the radio $2.64 \pm 1.42$, reading $2.64 \pm 1.27$ and cooking $1.97 \pm 1.55$. On the other hand, the five (5) least popular non-physical activities were facial massage $0.69 \pm 1.19$, sleeping, playing cards $1.17 \pm 1.288$, movies $1.84 \pm 1.48$ and exhibitions $1.28 \pm 1.02$.

TABLE 6: The correlation between age and years of service in non-physical activity among respondents $(\mathrm{N}=654)$

Factors
$\begin{gathered}\text { Non-Physical } \\ \text { activity }\end{gathered}$




\begin{tabular}{lcl}
\hline & $\mathbf{R}$ & $\mathbf{P}$ \\
\cline { 2 - 3 } Age & -0.173 & $0.001^{*}$ \\
$\begin{array}{l}\text { Years of } \\
\text { service }\end{array}$ & -0.110 & $0.005^{*}$ \\
* Significant level $p=0.05$ &
\end{tabular}

TABLE 7: Association between socio-demography and leisure participation in non-physical activity (N=654)

\begin{tabular}{llll}
\hline \hline Factors & Mean \pm SD & T & P value \\
\hline Ethnicity & & & \\
Malay & $28.96 \pm 8.87$ & -0.124 & \\
$\quad$ Non-Malay & $28.87 \pm 8.92$ & & \\
Religion & & & 0.601 \\
Islam & $28.82 \pm 8.88$ & 0.495 & \\
Non-Islam & $29.19 \pm 8.88$ & & \\
Marital status & & & 0.894 \\
Married & $28.96 \pm 8.43$ & -0.133 & \\
Single & $28.87 \pm 9.74$ & & $0.003^{*}$ \\
Position & & & \\
Senior lecturers & $28.36 \pm 8.85$ & 2.937 & 0.935 \\
Lecturers & $30.73 \pm 8.75$ & & \\
Country of origin & & & \\
$\quad$ Malaysia & $28.94 \pm 8.82$ & $0-086$ & \\
Non-Malaysia & $28.79 \pm 10.10$ & & \\
\hline
\end{tabular}

* Significant level $p<=0.05$

Association between socio-demography and leisure participation in non-physical activity

Furthermore, table 7 reveals the association between socio-demographic factors (ethnicity, religion, marital status, position and country of origin) with leisure participation in non- physical activity among participants. Significant associations was found in academic position ( $\mathrm{t}=2.937, p=0.003)$, although insignificant was found between ethnicity $(\mathrm{t}=-0.124, p=0.911)$, religion $(\mathrm{t}=0.495, \mathrm{p}=0.613)$, and marital status $(\mathrm{t}=-0.133, \mathrm{p}=0.904)$, with involvement in physical activities during leisure. Higher mean scores were obtained for the non-Malay (28.87 \pm 8.92$)$, non-Muslims (29.19 \pm 8.88$)$, married $(28.95 \pm 8.43)$ and lecturers $(30.73 \pm 8.75)$, compared to others.

Association between social support, time constraints, accessibility to facilities and health status with leisure participation in non-physical activity

Table 8 shows significant association between time constraints at home $(\mathrm{t}=2.368, \mathrm{p}=0.018)$. No association was found between social support from family $(\mathrm{t}=0.599, p=0.550)$, and friends $(\mathrm{t}=0.794, p=0.428)$, time constraints at work place $(\mathrm{t}=-0.350, p=0.724)$, accessibility to facilities at home $(\mathrm{t}=-0.633$, 
$p=0.527)$,accessibility to facilities at work place( $\mathrm{t}=-0.078, p=0.938)$, health status( $\mathrm{t}=-1.553, p=0.121)$, similarly respondents obtained high social support from family and friends had the highest mean score, $28.79 \pm 8.90$ and $28.74 \pm 8.91$, time constraints at home and time constraints in the workplace had the highest mean score, $28.42 \pm 9.15$ and $29.06 \pm 9.20$, accessibility to leisure related-facilities at home and accessibility to leisure related-facilities in the workplace had the highest mean score, $29.10 \pm 8.92$ and $28.94 \pm 8.82$ and with or without health problems had the highest mean score $29.38 \pm 8.98$ and $28.29 \pm 8.70$, respectively.

TABLE 8: Association between social support, time constraints, accessibility to facilities and health status with leisure participation (N654)

\begin{tabular}{|c|c|c|c|}
\hline Factors & Mean \pm SD & 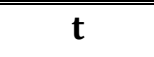 & P value \\
\hline \multicolumn{4}{|c|}{ Social support family } \\
\hline Low & $29.24 \pm 8.84$ & 0.599 & 0.550 \\
\hline High & $28.79 \pm 8.90$ & & \\
\hline \multicolumn{4}{|c|}{ Social support friends } \\
\hline Low & $29.32 \pm 8.82$ & 0.794 & 0.428 \\
\hline High & $28.74 \pm 8.91$ & & \\
\hline Low & $30.25 \pm 8.00$ & 2.368 & $0.018^{*}$ \\
\hline High & $28.42 \pm 9.15$ & & \\
\hline \multicolumn{4}{|c|}{ Time constraints at work } \\
\hline Low & $28.81 \pm 8.56$ & -0.350 & 0.724 \\
\hline High & $29.06 \pm 9.20$ & & \\
\hline \multicolumn{4}{|c|}{ Facility at home } \\
\hline Low & $28.66 \pm 8.82$ & -0.633 & 0.527 \\
\hline High & $29.10 \pm 8.92$ & & \\
\hline \multicolumn{4}{|c|}{ Facility at work } \\
\hline Low & $28.87 \pm 9.25$ & -0.078 & 0.938 \\
\hline High & $28.94 \pm 8.82$ & & \\
\hline Yes & $28.29 \pm 8.70$ & -1.553 & 0.121 \\
\hline No & $29.38 \pm 8.98$ & & \\
\hline
\end{tabular}

* Significant level $p=0.05$

\begin{abstract}
Multiple linear regressions showing the predictors of leisure participation in non-physical activity

Multiple linear logistic regression was completed to obtain factors predicting of leisure participation. Four variables were entered in the analysis using' ENTER 'method, only age was found to be significant at $p=<0.005$ and the final predictive model for leisure participation in non-physical activities among female academicians in UPM is: Non-physical Activity Score (NPAS) $=36.899$ - 0.211 Age. Table 8 reveals the final multiple linear regression models showing the predictors of leisure participation in non-physical activity. This model reveals that there is a reduction in the NPAS by $-0.211(95 \% \mathrm{CI}=-0.343$, - 0.213) for every year increase in age. However the model only explained $2.8 \%$ of non-physical leisure participation.
\end{abstract}

TABLE 8: Association between social support, time constraints, accessibility to facilities and health status with leisure participation $(\mathrm{N}=654)$

\begin{tabular}{lccccc}
\hline Factors & $\begin{array}{c}\text { Unstandardized } \\
\text { coefficient }\end{array}$ & $\begin{array}{c}\text { Standardized } \\
\text { coefficient }\end{array}$ & $\mathbf{T}$ & $\begin{array}{c}\mathbf{9 5 \%} \text { CI } \\
\text { Confidence }\end{array}$ & $\begin{array}{c}\text { Adjuste } \\
\mathbf{d ~ R}^{2}\end{array}$ \\
\hline & & & & \\
& & & $\mathbf{P}_{\text {Publishing }}^{\text {TAF }}$
\end{tabular}




\begin{tabular}{|c|c|c|c|c|c|c|c|c|}
\hline & B & SE & Beta & & Lower & Upper & & \\
\hline Constant & 36.899 & 2.478 & & 14.890 & 32.033 & 41.765 & $0.001^{*}$ & $2.8 \%$ \\
\hline Age & -0.211 & 0.067 & -0.203 & -3.149 & -0.343 & -0.213 & $0.001 *$ & \\
\hline
\end{tabular}

*Significant level $p=0.05$

\section{DISCUSSION}

The findings of this study is in support of a previous studies which shows that women face the challenges of inadequate participation in leisure activities [9]Furthermore, socio-demographic factors were found to influence the level of leisure participation among female academicians in UPM. In this study age was found to be significantly associated with leisure participation. The report from respondents shows that people of age 36 to 42 years obtained the highest scores for leisure participation while respondents of 50 years and above reported have lowest scores for leisure participation. This might be the majority of participants they are at young age. This corroborates with finding of [8] which report that among that age groups 24 to 40 years obtained highest scores. Another finding was similar with study of [9] that indicated ages of 24 to 34 years 22, 7\% reported higher scores compared to those 50 years and above $8.6 \%$.

Age was statistically significant with leisure participation $(\mathrm{t}=-7.53, p=<0.001)$ Porch et al., [10]. This study was also similar to previous study reported that, age range was a significant association with leisure participation $(\mathrm{F}=2.99$, $p=0.05$ ) [11]. This study also related with the write up of [12] that shown a significant difference between the age and leisure participation $(p=<0.001)$.

In contrast, a previous study reported that respondents of 50 to 54 (39.3\%) years reported higher leisure participation scores compared to any other age group Chen et al., [1].

On the other hand this study was not in line with the previous study reported about the insignificant association of age on leisure participation. We found from age classification, there is difference in nursing mother practice breastfeeding their have more responsibility compared women have other forms of feeding [13]. This corroborates with the finding of past studies that like age has no association in between leisure participation. This might be as a result of small sample size [14].

Furthermore in this study, a significant difference between ethnicity and leisure participation in physical activity was found, majority of the respondents were Malay. This corroborates with finding of [15], reported that Malays have 38.0\% recorded higher score than India 21.0\% low score. This study was similar to the report of [16] that Malays recorded the highest $64.6 \%$ of the respondents. This study is similar with past study reported Malay $99.3 \%$ reported high score of their respondents of [17]. This study is consistent with previous study that Malays record highest respondents of 357 (84.9\%) [18]. Similar to past study which reported that Malays have high scores of $71.6 \%$ of the participants [19].

Meanwhile similar studies shown that, significant association in leisure participation among ethnic [20-21]. This corroborates with finding of [22] who reported that ethnicity has a significant association with leisure physical 
activity $(p=<0.05)$. Another finding of study reported that, ethnicity was significant with leisure participation $(p=<0.05)$ [16].

The finding from this study reveals that, marital status has a significant association with leisure participation in physical activity; it also observed that married women having highest scores. The study was similar to past research indicates that, married women have higher score $71.32 \%$ than others [23]. This study is consistent with the past research reported that, married women have higher respondents 77.0\% Akbaraly et al., [24]. Meanwhile report from studies revealed that married $54.0 \%$ shows high respondents and single $46.0 \%$ having low response [12]. On the other hand the report from [25] shows that most respondents were married women. Compared with the report of [26] married women are less likely to participate in leisure activities than the singles.

This similar study with the finding of [16] reported that, marital status was significant with leisure participation $(p=<0.05)$ This corroborates with finding of [27] which reported that marital status has a statistically significant correlation with leisure participation $(\mathrm{r}=.16, p=<0.05)$. The finding of this study was similar with the study of [26] indicates, marital status is significant with leisure- activities. Similar study reported, a significant relationship between marital status and leisure physical activity [22]. On the other hand, study was not similar which reported that marital status was not significant with physical activity ( $p=>0.05$ ) which may be due to many responsibilities of a married women compared to unmarried ones [22].

The finding of this study indicates that social support from family members and friends have not significant association with leisure participation; but both of them have majority of participants in response of social support. Furthermore the insignificant of the result might due to study population or good socio-economic status of the participants and also majority of the respondents were together with their family members. Another findings from [28] reported that those who perceived high social support family members were $169(88.0 \%)$ and those with low social support family members were 23 $(12.0 \%)$. Meanwhile those who received high social support from friends were $96(50.0 \%)$, and those with low social support from friends were 96 (50.0\%) [28].

The result of this study is similar to previous research which shown there is no statistically significant difference between social support from family and friends with leisure activities ( $p=>0.05$ ) [29]. This study is in line with [30] which reveals that there was no significant association between social support and physical activity. No significance association was found with social support family, the difference could due be participants were immigrant and family were not staying with them [31].

On the other hand this findings is different from the study of [33] which shows there is significant correlation between social support family members and friends leisure physical activity. Social support received from family members and friends is significant with leisure physical activity according to [28].

As such, leisure non-physical activity in this study reveals that the popular leisure activities among 15 leisure activities participate by the respondents were browsing $48.7 \%$ attending exhibition $44.8 \%$ watching television $44.7 \%$, reading $37.7 \%$ and least was sewing. Another review similar to this study 
reported that the most common leisure activities carried out by their respondents were watching TV, listening to radio/song, books/journals, shopping and reading [2-16]. This study is not similar to previous research which reported that some women like sitting at home watching television rather than engaging in recreational activities, in addition Malaysian women have constraints in leisure activities especially the outdoor recreation.

[33] reported that people who are engage in regularly leisure activities such as reading, playing games, playing a musical device, or dancing were less likely to developed dementia in their old years, physical activity reduces $76.0 \%$ dementia. Survey was carried out among gender which reported that the regular leisure activities performed by female was non- physical activity which is watching television $80.5 \%$ and reading $58.0 \%$ these shows that aging women are more in non-physical activity than physical activity [28]. In a review by [34] in their study reported that people who spent so most time on watching TV has the higher risk of developed diabetes.

In same view, this study revealed that age, year of service, position and time constraints at home in non-physical activity was found to be significant association with leisure participation in non-physical activity. Meanwhile no association was found between social support from family and friends, time constraints at work place, accessibility to facilities at home and work place and health status. Similarly the insignificant results might attributed as a result of study population, all of the participants were female academicians, majority of them this is they common leisure activities performed or as result of more than half of respondents were Malays ethnic bias. However based on our knowledge this study is the first of its kind especially in association with non-physical activity and leisure participation in addition no studies was found associated with non-physical activity and leisure participation. However their some studies associated with single activities like reading and other leisure activities.

Limitations of this research include the study design, which would not allow findings to be generalized to the whole population of female academicians in Malaysia. Strengths of this study were achieved through the objectives of the study. Simple random sampling technique (SRS) was used in selecting the participants with a large sample size which attract a good response rate. For future studies more association should be conducted on non-physical activity with leisure participation.

\section{CONCLUSION AND RECOMMENDATIONS}

In conclusion this study was reveals that, female academician have less participation in leisure activities as it influence by socio-demographic factors such as age, marital status, ethnicity social support, time constraint, accessibility to facilities and health status. However participants in this study have good social support from both family members and friends but the level of participation still remain inconsistent. In view of that, further studies should be conducted to access more determinants in relationship to leisure participation among female academicians. The model of the study can only explained $9.8 \%$ and $2.8 \%$ of leisure participation.

However we recommended that more female academicians should be engaged and enlightening on the importance of leisure participation especially among women who advance in age, Married women and Malays 
ethnic should be encourage to involve in leisure participation more especially physical activity.

\section{Acknowledgement}

The author would like to thank reviewers for constructive comment and all the female academicians in Universiti Putra Malaysia for their participation.

This study was funded by Tawaran Geran Universiti Putra Malaysia UPM/700-2/1/GP-PS/2014/9433954

\section{REFERENCES}

1. Cheung MC, Ting W, Chan LY, Ho KS, Chan WM. Leisure participation and health-related quality of life of community dwelling elders in Hong Kong. Asian Journal of Gerontology and Geriatrics. 2009; 4: 15-23.

2. Oğuz D, Çakci I. Changes in leisure and recreational preferences: A case study of Ankara. Scientific Research and Essays. 2010; 5(8): 721-729.

3. World Health Organisation. Global strategy on diet, physical activity and health. Physical Activity and Women; 2014. Available from: http://www.who.int/dietphysicalactivity/factsheet_women/en/

4. Iwasaki Y, Zuzanek J, Mannell RC. The effects of physically active leisure on stress-health relationships. Canadian Journal of Public Health. 2001; 92(3): 214.

5. $\quad$ Coakley J. Sport in society: Issues \& controversies. Singapore: McGraw-Hill; 2001.

6. Oliveira AJ, Lopes CS, de Leon AC, Rostila M, Griep RH, Werneck GL, Faerstein E. Social support and leisure-time physical activity: longitudinal evidence from the Brazilian Pró-Saúde cohort study. International Journal of Behavioral Nutrition and Physical Activity. 2011; 8(1): 1-10.

7. 7. Due P, Holstein B, Lund R, Modvig J, Avlund K. Social relations: Network, support and relational strain. Social Science \& Medicine. 1999; 48(5): 661-673. D0I: 10.1016/S0277-9536(98)00381-5

8. Kaczynski AT, Henderson KA. Evidence about parks and recreation environmental correlates of physical activity: A review of evidence about parks and recreation. Leisure Sciences. 2007; 29(4): 315- 354. DOI: $10.1080 / 01490400701394865$

9. Lee B, Lawson KM, Chang PJ, Neuendorf C, Dmitrieva NO, Almeida DM. Leisure-time physical activity moderates the longitudinal associations between work-family spillover and physical health. Journal of Leisure Research. 2015; 47(4): 444-446.

10. Porch, T. C., Bell, C. N., Bowie, J. V., Usher, T., Kelly, E. A., LaVeist, T. A., \& Thorpe, R. J. (2015). The Role of Marital Status in Physical Activity Among African American and White Men. American Journal of Men's Health. 2015. D0I: $10.1177 / 1557988315576936$

11. Nyaupane GP, Andereck, KL. Understanding Travel Constraints: Application and Extension of a Leisure Constraints Model. 2008. DOI: 10.1016/S0261-5177(03)00096-7

12. Zhang HQ, Qu H, Tang VMY. A case study of Hong Kong residents' outbound leisure travel. Tourism Management. 2004; 25(2): 267-273. D0I: 10.1016/S0261-5177(03)00096-7

13. Chow HW, Dong YH. Relationship between participation in leisure activities and constraints on Taiwanese breastfeeding mothers during leisure activities. BMC Public Health. 2013; 13(1): 1. DOI: 10.1186/1471-2458-13410

14. Kok MO, Omar-Fauzee MS, Rosli MH. Relationship between level of physical activity and exercise imagery among Klang Valley Citizens. World Academy of Science, Engineering and Technology. 2010; 37: 712-716.

15. Cheah YK. Influence of socio-demographic factors on physical activity participation in a sample of adults in Penang, Malaysia. Malaysian Journal of Nutrition. 2011: 17(3): 385-391.

16. Minhat HS, Amin RM. Social support and leisure participation of elderly in Malaysia. The Internet Journal of Geriatrics and Gerontology. 2012; 7(1). 
17. Naharuddin NM, Sadegi M. Factors of workplace environment that affect employees performance: A case study of Miyazu Malaysia. International Journal of Independent Research and Studies. 2013; 2(2): 66-78.

18. Parsa M, Belgoorian $\mathbf{M}$ and Saeidi M. A study on indices of social capital and particiaption in sports among teenagers. Journal of Sports Management. 2013; 2: 109-127.

19. Minhat HSA, Amin RM. Continuity theory of ageing and leisure participation among elderly attending selected health clinics in Selangor. Medical Journal Malaysia. 2013; 12(2): 51-58.

20. Stodolska M, Shinew KJ. Environmental constraints on leisure time physical activity among Latino urban residents. Qualitative Research in Sport and Exercise. 2010; 2(3): 313-335. D0I: 10.1080/19398441.2010.517038

21. Chung T, Martin CS. Classification and course of alcohol problems among adolescents in addictions treatment programs. Alcoholism: Clinical and Experimental Research. 2001; 25(12): 1734-1742. D0I: 10.1111/j.15300277.2001.tb02184.x

22. Abdul Rahman H, Iskandar NH, Lim WK. Leisure time physical activities among adult attendees at a primary health care clinic. Malaysian Journal of Medicine and Health Sciences. 2007; 3(2): 29-36.

23. Pohb YKCBK. The determinants of participation in physical activity in Malaysia. Health and Research Perseption. 2014; 5(1): 25-27.

24. Akbaraly TN, Portet F, Fustinoni S, Dartigues JF, Artero S, Rouaud O, Touchon J, Ritchie K, Berr C, "Leisure activities and the risk of dementia in the elderly results from the Three-City Study." Neurology. 2009; 73(11): 854-861. DOI: 10.1212/WNL.0b013e3181b7849b

25. Achour M, Grine F, Roslan Mohd Nor M. Work-family conflict and coping strategies: Qualitative study of Muslim female academicians in Malaysia. Mental Health, Religion \& Culture. 2014; 17(10): 1002-1014. D0I: 10.1080/13674676.2014.994201

26. Ding D, Sallis JF, Hovell MF, Du J, Zheng M, He H, Owen N. Physical activity and sedentary behaviours among rural adults in Suixi, China: a cross-sectional study. International Journal of Behavioral Nutrition and Physical Activity. 2011; 8(1): 37. DOI: 10.1186/1479-5868-8-37

27. Yang $\mathrm{CH}$, Chen $\mathrm{KH}$, Lee CJ. Using Rasch model to explore the perceived constraints of outbound travel for individual travelers. J. Leisure Tourism Industry Res. 2007; 2(1): 1-26.

28. Minhat HS, Amin RM, Shamsuddin K. Determinants of Leisure Participation among the Malay Ethnic Elderly in Malaysia Department of Community Health. Faculty of Medicine and Health Sciences, Of Scientific Research. 2014; 21(9): 1442-1447.

29. Eather N, Morgan PJ, Lubans DR. Social support from teachers mediates physical activity behavior change in children participating in the Fit-4-Fun intervention. International Journal of Behavioral Nutrition and Physical Activity. 2013; 10(68). DOI: 10.1186/1479-5868-10-68

30. Pan SY, Cameron C, DesMeules M, Morrison H, Craig CL, Jiang X. Individual, social, environmental, and physical environmental correlates with physical activity among Canadians: A cross-sectional study. BMC Public

Health. 2009; 9(1): 1. DOI: 10.1186/1471-2458-9-21

31. Marquez DX, McAuley E. Social cognitive correlates of leisure time physical activity among Latinos. Journal of Behavioral Medicine. 2006; 29(3): 281-289. DOI: 10.1007/s10865-006-9055-6

32. Prochaska JJ, Rodgers MW, Sallis JF. Association of parent and peer support with adolescent physical activity. Research Quarterly for Exercise and Sport.2002; 73(2): 206-210. D0I: 10.1080/02701367.2002.10609010

33. Robins PV. Johns Hopkin 2006 white paper on memory. Medletter Associate: 2006.

34. Hu FB, Leitzmann MF, Stampfer MJ, Colditz GA, Willett WC, Rimm EB. Physical activity and television watching in relation to risk for type 2 diabetes mellitus in men. Archives of Internal Medicine. 2001; 161(12): 1542-1548. DOI: 10.1001/archinte.161.12.1542

— This article does not have any appendix. - 